\title{
Reliability of Thyroid Imaging Reporting and Data System (TI-RADS), and Ultrasonographic Classification of the American Thyroid Association (ATA) in Differentiating Benign from Malignant Thyroid Nodules
}

\author{
SHERIF H. ABOU GAMRA, M.D.; SAMAR R. RAGHEB, M.D. and MAI M.I. SALAMA, M.Sc. \\ The Department of Radiology, Faculty of Medicine, Ain Shams University
}

\begin{abstract}
Background: Thyroid nodules are a frequent finding on necksonography. Ultrasound is the most commonly used imaging technique for the evaluation of thyroid nodules. Thyroid nodules are vastly prevalent whereas thyroid cancer is a relatively rare entity.
\end{abstract}

Aim of Study: The aim of this study is to evaluate the risk stratification system used by the American College of Radiology (ACR) Thyroid Imaging, Reporting and Data System (TI-RADS).

Patients and Methods: Across sectional study, the study setting was conducted at Ain Shams University Hospitals, from January 2020 till July 2020. This study was performed on random sample of 30 patients have thyroid nodules were included in this study.

Results: In this study was found that $66.7 \%$ of the malignant nodules had smooth margins and $33.3 \%$ of the malignant nodules had lobulated or irregular nodules. Also, it was found that of the 31 benign nodules included in our study, 20 nodules $(64.5 \%)$ had smooth margins and 11 nodules $(35.5 \%)$ had ill defined margins; showing significant increase in benign group than malignant group. In this study, the results to were comparable those reported in other studies, $11.1 \%$ of the malignant nodules had no echogenic foci, $11.1 \%$ of the malignant nodules had macrocalcifications, $11.1 \%$ of the malignant nodules had peripheral calcifications, $66.7 \%$ of the malignant nodules had punctate echogenic foci. Nodules with no echogenic foci had a statistically significant increase in benign group than malignant group.

Conclusion: The ACR TI-RADS scoring system is a simple and practical method for assessing thyroid nodules and has shown an excellent diagnostic accuracy for the diagnosis of malignant thyroid nodules in the present study.

Key Words: Thyroid Imaging Reporting Data System - Ultrasonographic Classification - American Thyroid Association - Differentiating Benign Malignant Thyroid Nodules.

Correspondence to: Dr. Sherif H. Abou Gamra, The Department of Radiology, Faculty of Medicine, Ain Shams University

\section{Introduction}

THYROID nodules are vastly prevalent whereas thyroid cancer is a relatively rare entity. While thyroid nodules are discovered on clinical examination in $3-7 \%$ of the adult population, the incidence of detectable nodules on Ultrasound (US) is between $30 \%$ and $70 \%$, and rises progressively with age. However, only less than $10 \%$ of these ultrasound detected nodules are malignant [1].

As an easy simple way to diagnose nodules we use ultrasound, but its ability to differentiate benign from possible malignant nodules was an obstacle. There are several recently published guidelines for determining whether a nodule should undergo USguided Fine-Needle Aspiration Cytology (FNAC) on the basis of its US [2].

Risk classification models based on US features have been created by multiple professional societies, including the American College of Radiology (ACR), which published the Thyroid Imaging Reporting and Data System (TI-RADS) in 2017 [3].

ACR TI-RADS uses a standardized lexicon for assessment of thyroid nodules to generate a numeric scoring of features, designate categories of relative probability of benignity or malignancy, and provide management recommendations, with the aim of reducing unnecessary biopsies and excessive surveillance [4].

Aim of the work:

The aim of this study is to evaluate the risk stratification system used by the American College 
of Radiology (ACR) Thyroid Imaging, Reporting and Data System (TI-RADS).

\section{Patients and Methods}

Type of study: Cross sectional study.

Study setting: The study was conducted at Ain Shams University Hospitals.

Study period: From January 2020 till July 2020.

\section{Study population:}

\section{Inclusion criteria:}

- Patients with one or more thyroid nodules that meet the TI-RADS.

- Age group: Ranges from 27 to 69 years.

\section{Exclusion criteria:}

- Patients with thyroid nodules less than $1 \mathrm{~cm}$.

- Patients with contraindications to fine needle aspiration cytology or surgery, e.g.: Abnormal bleeding profile.

Sampling method: This study was performed on simple random sample.

Sample size: A total of 30 patients were included in the study, 6 males (20\%) and 24 females (80\%). The mean patient age was $44.48 \pm 11.04$ years (range: 25-69 years).

Informed oral consent explaining the procedure details was obtained from all patients prior to inclusion in the study. The study was conducted according to the stipulations of the ASU ethical and scientific committee. The privacy of participants and confidentiality of data was guaranteed during the various phases of the study.

\section{Study tools and procedures:}

- Detailed explanation of the procedure and obtaining consent.

- All patients were subjected to full history taking prior to scanning.

\section{Thyroid Ultrasound:}

Ultrasound of the thyroid gland was performed in 3 ultrasound machines (LOGIQTM P7 and P9, GE Healthcare and Accuvix XG, Samsung) using a highfrequency probe (7-10MHz). Axial and sagittal ultrasound scanning of the thyroid nodules with the head slightly extended was performed.

Imaging interpretation of thyroid nodules was done, guided by the American College of Radiology
(ACR) Thyroid Imaging, Reporting and Data System (TI-RADS) template as follows:

1- Composition.

2- Echogenicity.

3- Shape.

4- Margin.

5- Presence of echogenic Foci.

Points from all TI-RADS categories were added to determine TI-RADS Level as follows:

The nodule with the highest TI-RADS score in patients having multiple nodules was included in the study.

Criteria to confirm the nature of the scanned thyroid nodules (either benign or malignant) by Fine Needle Aspiration Cytology (FNAC) report.

\section{Thyroid Fine Needle Aspiration Cytology (FNAC):}

FNAC was undertaken by a radiologist with ultrasound guidance after the thyroid ultrasound. The procedure was explained carefully to the patient. The patient was placed in a supine position with head is turned, chin extended, away from the side to be biopsied to allow easier access. The transducer was placed directly over the lesion and the patient was instructed not to swallow or speak during the insertion of the needle. FNAC was performed using a 26 gauge needle attached to a $10 \mathrm{ml}$ syringe. Two to three aspirations were performed on each nodule. Cytology smears were prepared on three to six slides. Slides were fixed immediately in 95\% alcohol and sent for cytopathology. A cytology technician confirmed the adequacy of the specimen before being reported by cytopathologists.

\section{Statistical analysis:}

Data were collected, revised, coded and entered to the Statistical Package for Social Science (IBM SPSS) version 23. The quantitative data were presented as mean, standard deviations and ranges when their distribution found parametric while with non parametric distribution were presented as median with Inter-Quartile Range (IQR). Also qualitative data were presented as number and percentages. So, the $p$-value was considered significant as the following: $p$-value $>0.05$ : Non significant, $p$-value <0.05: Significant, $p$-value $<0.01$ : Highly significant.

\section{Results}

A total of 30 patients were included in the study, 6 males (20\%) and 24 females (80\%) Fig. (1). The 
mean patient age was $44.48 \pm 11.04$ years (range: 25-69 years).

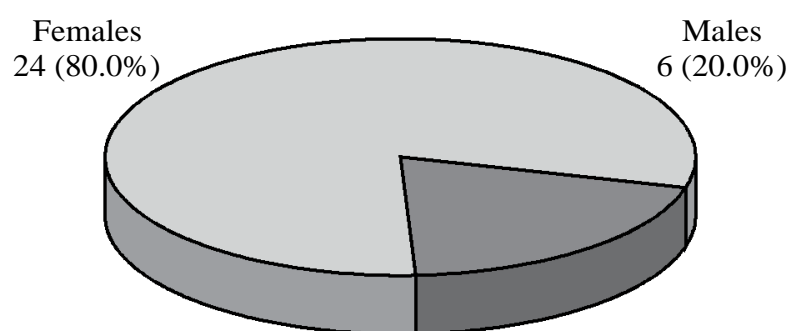

Fig. (1): Pie chart demonstrating percentage of male and female patients.

Table (1) shows that there was no statistically significant difference found between the two studied groups regarding gender and age of the studied cases.

Table (1): Demonstrating comparison between benign group and malignant group regarding age and sex of the studied cases.

\begin{tabular}{lllllll}
\hline & \multicolumn{2}{c}{$\begin{array}{c}\text { Benign } \\
(\mathrm{n}=27)\end{array}$} & \multicolumn{2}{c}{$\begin{array}{c}\text { Malignant } \\
(\mathrm{n}=3)\end{array}$} & $\begin{array}{c}\text { Test } \\
\text { of sig. }\end{array}$ & $p$ \\
\cline { 2 - 5 } & No. & $\%$ & No. & $\%$ & & \\
\hline $\begin{array}{l}\text { Sex: } \\
\quad \text { Male }\end{array}$ & 22 & 81.5 & 2 & 66.7 & $\chi^{2}=$ & 0.501 \\
$\quad$ Female & 5 & 18.5 & 1 & 33.3 & 0.370 & \\
Age (years): & & & & & & \\
$<60$ & 24 & 88.9 & 2 & 66.7 & $\chi^{2}=$ & $\mathrm{FE}_{p=}=$ \\
$>60$ & 3 & 11.1 & 1 & 33.3 & 1.154 & 0.360 \\
$\quad \begin{array}{l}\text { Mean } \pm \text { SD. } \\
\text { Range }\end{array}$ & $49.74 \pm 11.32$ & $41.67 \pm 23.69$ & $t=0.583$ & 0.616 \\
\hline & $30-65$ & & $27-69$ & & & \\
\hline
\end{tabular}

Table (2) shows that there was statistically significant increase in the incidence of cystic as well as mixed cystic in benign group than malignant group, while there was statistically high significant increase in the incidence of solid thyroid nodules in malignant group than benign group.

Table (2): Comparison between benign group and malignant group the according to composition.

\begin{tabular}{|c|c|c|c|c|c|c|}
\hline \multirow[t]{2}{*}{ Composition } & \multicolumn{2}{|c|}{$\begin{array}{l}\text { Benign } \\
(\mathrm{n}=27)\end{array}$} & \multicolumn{2}{|c|}{$\begin{array}{l}\text { Malignant } \\
\quad(\mathrm{n}=3)\end{array}$} & \multirow{2}{*}{$x^{2}$} & \multirow[t]{2}{*}{$\mathrm{MC}_{p}$} \\
\hline & No. & $\%$ & No. & $\%$ & & \\
\hline $\begin{array}{l}\text { - Cystic or almost } \\
\text { completely cystic }\end{array}$ & 6 & 22.2 & 0 & 0.0 & 1.683 & 1.000 \\
\hline - Spongiform & 1 & 3.7 & 0 & 0.0 & & \\
\hline $\begin{array}{l}\text { - Mixed Cystic and } \\
\text { solid }\end{array}$ & 7 & 25.9 & 1 & 33.3 & & \\
\hline $\begin{array}{l}\text { - Solid or almost } \\
\text { completely solid }\end{array}$ & 13 & 48.1 & 2 & 66.7 & & \\
\hline
\end{tabular}

(Table 3 ) shows that there was statistically high significant increase in the incidence of wider than taller in benign group than malignant group.
Table (3): Comparison between benign group and malignant group according to shape.

\begin{tabular}{llllllll}
\hline \multirow{2}{*}{ Shape } & \multicolumn{2}{c}{$\begin{array}{c}\text { Benign } \\
(\mathrm{n}=27)\end{array}$} & & \multicolumn{2}{c}{$\begin{array}{c}\text { Malignant } \\
(\mathrm{n}=3)\end{array}$} & $\chi^{2}$ & $\mathrm{FE}_{\boldsymbol{p}}$ \\
\cline { 2 - 3 } & No. & $\%$ & & No. & $\%$ & & \\
\hline Wider than taller & 27 & 100.0 & & 1 & 33.3 & $19.286^{*}$ & $0.007^{*}$ \\
Taller than wider & 0 & 0.0 & & 2 & 66.7 & & \\
\hline
\end{tabular}

There was statistically significant increase in the incidence of nodules having smooth margins in benign group than malignant group, while there was statistically high significant increase in the incidence of nodules having irregular margins in malignant group than benign group (Table 4).

Table (4): Comparison between benign group and malignant group according to margins.

\begin{tabular}{|c|c|c|c|c|c|c|}
\hline \multirow[t]{2}{*}{ Margins } & \multicolumn{2}{|c|}{$\begin{array}{l}\text { Benign } \\
(\mathrm{n}=27)\end{array}$} & \multicolumn{2}{|c|}{$\begin{array}{l}\text { Malignant } \\
(\mathrm{n}=3)\end{array}$} & \multirow[t]{2}{*}{$x^{2}$} & \multirow[t]{2}{*}{$\mathrm{FE}_{p}$} \\
\hline & No. & $\%$ & No. & $\%$ & & \\
\hline Smooth & 27 & 100.0 & 2 & 66.7 & 9.310 & 0.100 \\
\hline Ill-defined & 0 & 0.0 & 1 & 33.3 & & \\
\hline
\end{tabular}

There was statistically significant increase in the incidence of thyroid nodules with no calcifications and thyroid nodules with large comet tail artifacts in benign group than malignant group, while there was statistically high significant increase in the incidence of thyroid nodules with punctuate echogenic foci in malignant group than benign group as show in (Table 5).

Table (5): Comparison between benign group and malignant group according to presence of echogenic foci.

\begin{tabular}{lllllll}
\hline $\begin{array}{l}\text { Presence of } \\
\text { echogenic foci }\end{array}$ & $\begin{array}{c}\text { Benign } \\
(\mathrm{n}=27)\end{array}$ & \multicolumn{2}{c}{$\begin{array}{c}\text { Malignant } \\
(\mathrm{n}=3)\end{array}$} & \multirow{2}{*}{$\chi^{2}$} & $\mathrm{MC}_{p}$ \\
\cline { 2 - 5 } & No. & $\%$ & No. & $\%$ & & \\
\hline - None & 23 & 85.2 & 1 & 33.3 & 8.206 & 0.059 \\
$\begin{array}{l}\text { - Large comet tail } \\
\text { artifacts }\end{array}$ & 2 & 7.4 & 0 & 0.0 & & \\
- Macro calcifications & 2 & 7.4 & 1 & 33.3 & & \\
$\begin{array}{l}\text { - Peripheral (rim) } \\
\text { calcifications }\end{array}$ & 0 & 0.0 & 0 & 0.0 & & \\
- Punctuate echogenic & 0 & 0.0 & 1 & 33.3 & & \\
$\quad$ foci & & & & & & \\
\hline
\end{tabular}

Table (6) illustrate the diagnostic performance of TI-RADS level which demonstrating the diagnostic performance of Thyroid Imaging, Reporting and Data System (TI-RADS) shows that the best cut off point to detect malignant cases was 3 (that corresponds to TI-RADS level 4) with sensitivity of $66.67 \%$, specificity of $77.78 \%$ ) as illustrate in chart ROC curve show in Fig. (2). 
Table (6): Demonstrating comparison between benign group and malignant group regarding the total points and TI-RADS level.

\begin{tabular}{|c|c|c|c|c|c|c|c|c|c|}
\hline & \multirow{2}{*}{ AUC } & \multirow{2}{*}{$p$-value } & \multicolumn{2}{|c|}{$95 \%$ C.I } & \multirow{2}{*}{ Cut off } & \multirow{2}{*}{ Sensitivity } & \multirow{2}{*}{ Specificity } & \multirow{2}{*}{ PPV } & \multirow{2}{*}{ NPV } \\
\hline & & & L.L & U.L & & & & & \\
\hline TI RAS level & 0.809 & 0.084 & 0.547 & 1.071 & $>3$ & 66.67 & 77.78 & 25.0 & 95.5 \\
\hline
\end{tabular}

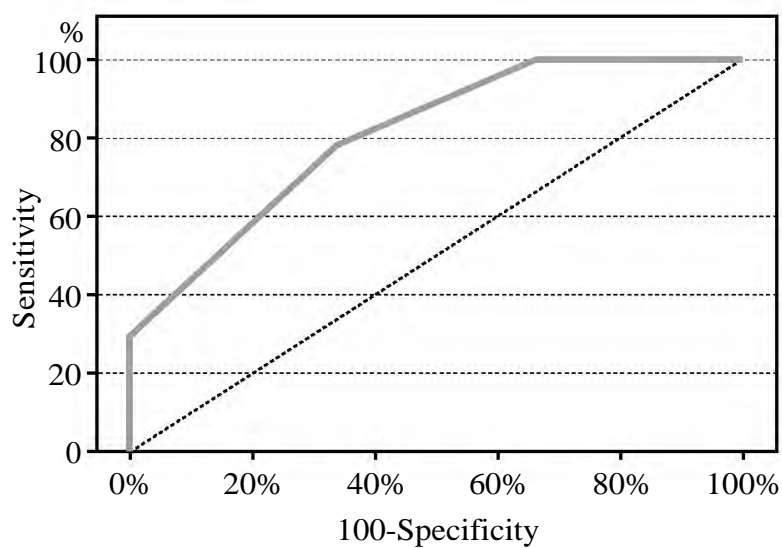

Fig. (2): Chart ROC curve demonstrating the diagnostic performance of TI-RADS level.

Fig. (3) show a 27 years old female with a smooth hypoechoic nodule, mixed cystic and solid,wider than taller (TI-RADS: 3), (FNAC: Follicular propably colloid nodules with adenomatous hyperplastic changes).

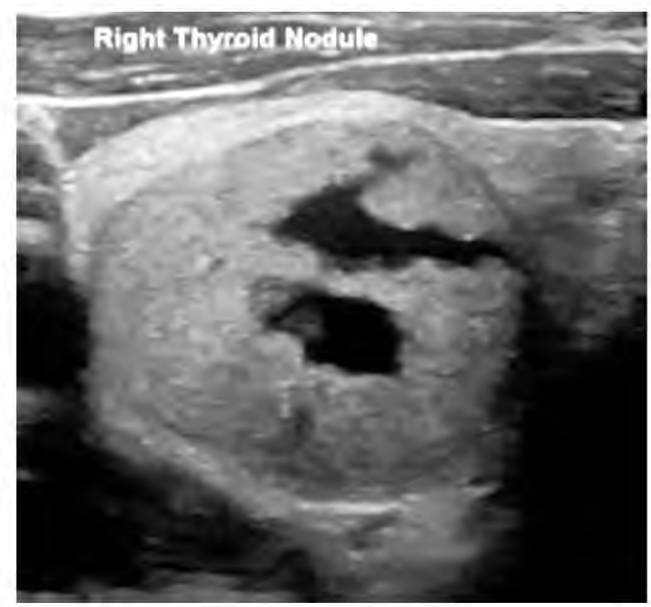

Fig. (3): A smooth hypoechoic nodule, mixed cystic and solid, wider than taller at right lobe.

Fig. (4) show a 46 years old male patient with a smooth anechoic nodule at right lobe, wider than taller, present large comet tail artifacts (TI-RADS level: TR 1), (FNAC: Colloid cyst).

Fig. (5) show a 44 years old male patient with multiple thyrod nodules. The nodule having the highest score is seen at the left lobe with characteristic smooth border, hyperechoic, wider than taller and presence of macrocalification (TI-RADS level: TR 4) (FNAC: LEFT: Colloid nodule with hyperplastic changes. RIGHT: Colloid nodule with cystic change).

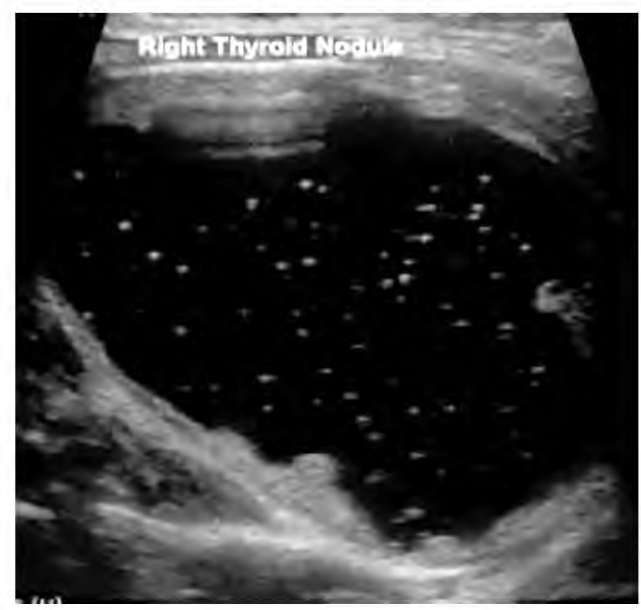

Fig. (4): A smooth anechoic nodule at right thyroid lobe.

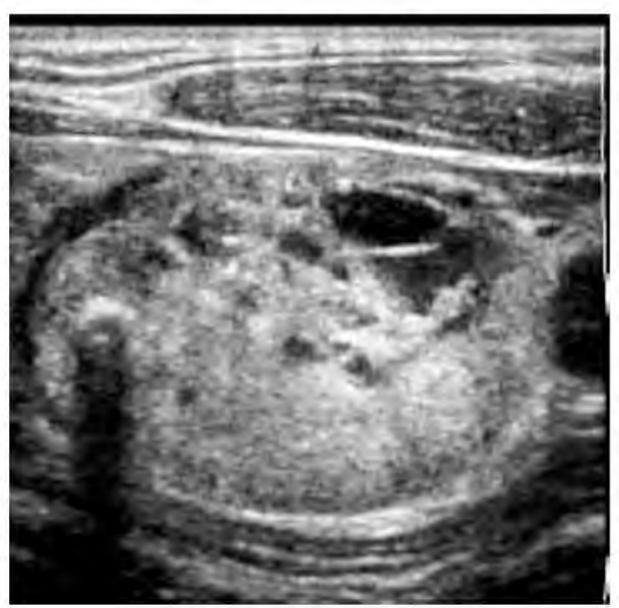

Fig. (5): A nodule at the left lobe with characteristic smooth border, hyperechoic, wider than taller and presence of macrocalification.

\section{Discussion}

Thyroid nodules are frequent among the general population. Ultrasound is the most commonly used imaging technique in the evaluation of thyroid nodules and its use has increased the discovery of nodules greatly [2].

Many previous studies have proven the usefulness of ultrasound evaluation of thyroid nodules 
and its ability to differentiate benign from malignant nodules. Currently, there are several systems of sonographic patterns for thyroid nodule risk stratification. A committee of experts organized under the auspices of the American College of Radiology (ACR) has developed recently Thyroid Imaging Reporting and Data System (TI-RADS) guidelines, modeled on the well-known BI-RADS approach that became a worldwide accepted method that guides clinical management of breast lesions [5].

The establishment of a lexicon is an essential initial step that provides a structured method for evaluation of thyroid nodules [2].

Other classification systems have also been published. The first TI-RADS system was described by Horvath et al. [6] and included six categories. Another more practical and less complex TI-RADS system was developed by Kwak et al. [7] based on the number of suspicious ultrasound features. A third TIRADS classification was proposed by Russ et al. [8] using a six-point scale.

A critical step in developing the ACR TI-RADS guidelines and all other similar guidelines is stratification of lesions on the basis of their risk of malignancy [9].

The ACR TI-RADS guidelines were developed to facilitate a standard approach to assess nodular features and to decrease the variation seen in reporting of thyroid nodules in current practice among interpreters with varying levels of sonographic expertise and also to develop guidelines for further management on the basis of the nodular features in the lexicon. When assessing a nodule, one feature is selected from each of the first four categories (composition, echogenicity, shape, margins) and all the features that apply from the final category (presence of echogenic foci). Each feature is assigned an individual point that scale with the risk of malignancy. The points for all five categories are summed to determine the overall TI-RADS level that ranges from one to five according to the risk of malignancy, with more suspicious features being awarded additional points. For each level, a specific size cutoff for FNA is recommended [10].

The aim of this study is to evaluate the risk stratification system used by the American College of Radiology (ACR) Thyroid Imaging, Reporting and Data System (TI-RADS).

Other TI-RADS classification systems that have been published were not evaluated in the present study. Therefore, this study only account for TI-
RADS developed by the American college of Radiology (ACR). To achieve these aims, the study included 30 thyroid nodules. Imaging interpretation was done guided by the ACR TI-RADS template, focusing on their sonographic appearance in relation to their benign or malignant nature. Similar to previous reports, this study showed that allocation of points for different sonographic findings mirror the likelihood that those findings are associated with malignancy.

As regards the composition, Henrichsen et al., [11] found that there is uncommon for cancers to have a predominantly cystic appearance Frates et al., [12] and Moon et al., [13] found that pure cysts and spongiform nodules are always benign Ahn et al., [14] found that thyroid cancers are more likely to be solid or nearly entirely solid.

In agreement with the previous reports, almost all nodules with cystic changes included in the study were benign, while there was high significant increase in the incidence of solid nodules in malignant group than benign group. As regards the echogenicity, this study substantiated the findings of previous studies done by Kwak et al. [7], that showed that the risk of malignancy is inversely proportional to nodule echogenicity.

Classic papillary and medullary thyroid cancers appear hypoechoic due to increased cellular compaction [15]. However, not all neoplasms of the thyroid are hypoechoic. Follicular neoplasms, including benign follicular adenomas, follicular carcinomas, and follicular variant of papillary cancers, are composed of small micro-follicles.

Therefore, the echogenicity of these follicularpredominant neoplasms, both carcinomas and adenomas, is less commonly hypoechoic and instead is much more commonly isoechoic [16].

In agreement with previous studies, there was a significant increase in the incidence of anechoic and hyperechoic nodules in benign group than malignant group. As regards the margin, William et al., [9] found that $12.9 \%$ of nodules with smooth margins and $44.7 \%$ of nodules with lobulated or irregular nodules were malignant. Moon et al., [13] reported that an ill-defined thyroid nodule margin is not associated with malignancy Kim et al., [17] reported that irregular and lobulated margins are suspicious for thyroid malignancy Ito et al., [18] reported that it is important to assess extrathyroidal extension when evaluating thyroid malignancy.

In this study, the results were comparable to those reported in other studies. It was found that 
$66.7 \%$ of the malignant nodules had smooth margins and $33.3 \%$ of the malignant nodules had lobulated or irregular nodules. Also, it was found that of the 31 benign nodules included in our study, 20 nodules $(64.5 \%)$ had smooth margins and 11 nodules $(35.5 \%)$ had ill defined margins; showing significant increase in benign group than malignant group.

As regards the shape, previous studies have reported that thyroid cancer is associated with a nodule's anteroposterior to transverse diameter ratio being greater than one as measured on the transverse view with a specificity ranging from 82 to $93 \%[\mathbf{1 4 , 1 9 ]}$.

As regards the shape, previous studies have reported that thyroid cancer is associated with a nodule's anteroposterior to transverse diameter ratio being greater than one as measured on the transverse view with a specificity ranging from 82 to $93 \%[\mathbf{1 4 , 1 7 , 1 9 ]}$.

In agreement with previous studies, there was statistically high significant increase in the incidence of wider than taller nodules in benign group than malignant group. As regards the presence of echogenic foci, a previous study done by William et al., [9] found that the risk of malignancy associated with no echogenic foci, macrocalcifications, peripheral calcifications, and punctate echogenic foci in solid nodules was $9.7 \%, 11.8 \%, 20.2 \%$, and $35.0 \%$, respectively.

In this study, the results to were comparable those reported in other studies, $11.1 \%$ of the malignant nodules had no echogenic foci, $11.1 \%$ of the malignant nodules had macrocalcifications, $11.1 \%$ of the malignant nodules had peripheral calcifications, $66.7 \%$ of the malignant nodules had punctate echogenic foci. Nodules with no echogenic foci had a statistically significant increase in benign group than malignant group.

Previous studies done by Malhi et al., [20] found a strong association between the presence of large comet-tail artifacts in cystic or partially cystic nodules and benignity. In agreement with the previous studies, all cystic nodules having comet tail artifacts were benign. This study agreed with Reading et al., [21] that macrocalcifications were found within both benign and malignant nodules yet more in the benign nodules. In benign nodules, these dystrophic calcifications were present in areas of fibrosis and tissue degeneration. However, in malignant nodules, these coarse calcifications were associated with the presence of punctate echogenic foci.
As regards the diagnostic accuracy of TI-RADS scoring system, the risk thresholds established by the ACR, guided by evaluation of a study that included a database of more than 3,000 proven thyroid nodules showed cancer risk levels of no more than $2 \%$ for TR 1 and TR2 nodules, $5 \%$ for TR3 nodules, $5.1 \%$ to $20 \%$ for TR 4 nodules, and at least $20 \%$ for TR5 nodules [10].

A recent study done by William et al., [9] that included 3822 nodules in 3315 patients, 352 of which were malignant, found that the risk levels of malignancy for TR1, TR2, TR3, TR4, and TR5 nodules were $0.3 \%, 1.5 \%, 4.8 \%, 9.1 \%$, and $35.0 \%$, respectively. A statistically significant trend of an increasing risk of malignancy was noted as the score of the total points increased and as the final TI-RADS level increased from TR1 to TR5.

Substantial agreement has been found among the study results and the previous studies. In this study, the best cut off point to detect malignant cases was 3 (corresponding to TI-RADS level 3) with sensitivity of $66.67 \%$, specificity of $77.78 \%$, Positive Predictive Value (PPV) of $25 \%$ and Negative Predictive Value (NPV) of $95.5 \%$. A statistically significant trend of an increasing risk of malignancy was noted as the total points increased ( $p$-value $<0.084)$ and as the final TI-RADS level increased from TR1 to TR5 ( $p$-value $<0.084$ ).

\section{Conclusion:}

The ACR TI-RADS scoring system is a simple and practical method for assessing thyroid nodules and has shown an excellent diagnostic accuracy for the diagnosis of malignant thyroid nodules in the present study.

\section{References}

1- CASTRO M.R., ESPIRITU R.P., BAHN R.S., et al.: Predictors of malignancy in patients with cytologically suspicious thyroid nodules. Thyroid., 21 (11): 1191-8, 2011.

2- GRANT E.G., TESSLER F.N., HOANG J.K., et al.: Thyroid ultrasound reporting lexicon: White paper of the ACR Thyroid Imaging, Reporting and Data System (TIRADS) Committee. J. Am. Coll. Radiol., 12 (12 Pt A): 1272-9, 2015.

3- MACEDO B.M., IZQUIERDO R.F., GOLBERT L., et al.: Reliability of Thyroid Imaging Reporting and Data System (TI-RADS), and ultrasonographic classification of the American Thyroid Association (ATA) in differentiating benign from malignant thyroid nodules. Archives of endocrinology and metabolism, 62 (2): 131-8, 2018.

4- TAPPOUNI R.R., ITRI J.N., McQUEEN T.S., et al.: ACR TI-RADS: Pitfalls, solutions, and future directions. RadioGraphics, 39 (7): 2040-52, 2019. 
5- CHANDRAMOHAN A., KHURANA A., PUSHPA B.T., et al.: Is TIRADS a practical and accurate system for use in daily clinical practice? Indian J. Radiol. Imaging, 26: 145-52, 2016.

6- HORVATH E., MAJLIS S., ROSSI R., et al.: An ultrasonogram reporting system for thyroid nodules stratifying cancer risk for clinical management. J. Clin. Endocrinol. Metab., 94 (5): 1748-51, 2009.

7- KWAK J.Y., JUNG I., BAEK J.H., et al.: Image reporting and characterization system for ultrasound features of thyroid nodules: Multicentric Korean retrospective study. Korean J. Radiol., 14 (1): 110-7, 2013.

8- RUSS G., ROYER B., BIGORGNE C., et al.: Prospective evaluation of thyroid imaging reporting and data system on 4550 nodules with and without elastography, 168: 649$55,2013$.

9- WILLIAM D.M., SHARLENE A.T., CARL C.R., et al.: Multiinstitutional Analysis of Thyroid Nodule Risk Stratification with TIRADS. American Roentgen Ray Society, 208: 1331-41, 2017.

10- TESSLER F.N., MIDDLETON W.D., GRANT E.G., et al.: ACR Thyroid Imaging, Reporting and Data System (TI-RADS): White Paper of the ACR TI-RADS Committee. Journal of the American College of Radiology: JACR, 14 (5): 587-95, 2017.

11- HENRICHSEN T.L., READING C.C., CHARBONEAU J.W., et al.: Cystic change in thyroid carcinoma: Prevalence and estimated volume in 360 carcinomas. J. Clin. Ultrasound, 38 (7): 361-6, 2010.

12- FRATES M.C., BENSON C.B., DOUBILET P.M., et al.: Prevalence and distribution of carcinoma in patients with solitary andmultiple thyroid nodules on sonography. J. Clin. Endocrinol. Metab., 91 (9): 3411-7, 2006.

13- MOON W.J., JUNG S.L., LEE J.H., et al.: Benign and malignant thyroid nodules: US differentiation-multicenterretrospective study. Radiology, 247 (3): 762-70, 2008.

14- AHN S.S., KIM E.K., KANG D.R., et al.: Biopsy of thyroid nodules: Comparison of three sets of guidelines. A.J.R. Am. J. Roentgenol., 194 (1): 31-7, 2010.

15- KOVACEVIC O. and SKURLA M.S.: Sonographic diagnosis of thyroid nodules: Correlation with the results of sonographicallyguided fine-needle aspiration biopsy. J. Clin. Ultrasound., 35 (2): 63-7.ne/AS 24, 2007.

16- JEH S.K., JUNG S.L., KIM B.S., et al.: Evaluating the degree of conformity of papillary carcinoma and follicular carcinoma to the reported ultrasonographic findings of malignant thyroid tumor. Korean J. Radiol., 8 (3): 1927, 2007.

17- KIM E.K., PARK C.S., CHUNG W.Y., et al.: New sonographic criteria for recommending fine needle aspiration biopsy ofnonpalpable solid nodules of the thyroid. A.J.R. Am. J. Roentgenol., 178 (3): 687-91, 2002.

18- ITO Y., KOBAYASHI K., TOMODA C., et al.: Ill-defined edge on ultrasonographic examination can be a marker of aggressive characteristic of papillary thyroid microcarcinoma. World J. Surg., 29 (8): 1007-11, 2005.

19- CAPPELLI C., PIROLA I., CUMETTI D., et al.: Is the anteroposterior and transverse diameter ratio of nonpalpable thyroid nodules a sonographic criteria for recommending fineneedle aspiration cytology? Clin. Endocrinol., 63 (6): 689-93, 2005.

20- MALHI H., BELAND M.D., CEN S.Y., et al.: Echogenic foci in thyroid nodules: Significance of posterior acoustic artifacts. A.J.R. Am. J. Roentgenol., 203 (6): 1310-6, 2014.

21- READING C.C., CHARBONEAU J.W., HAY I.D., et al.: Sonography of thyroid nodules: A "classic pattern" diagnostic approach. Ultrasound Q., 21 (3): 157-65, 2005. 


\section{دقة نظام تقرير ومعلومات تصوير الغلدة الدرقية،

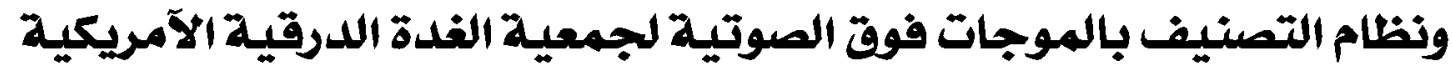

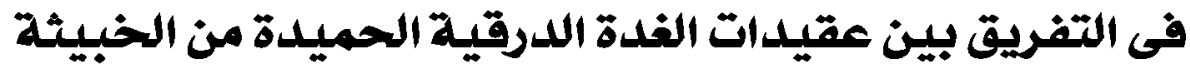

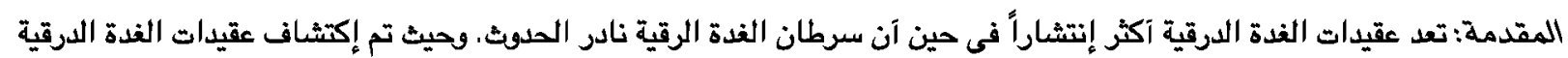

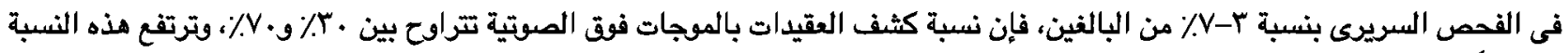

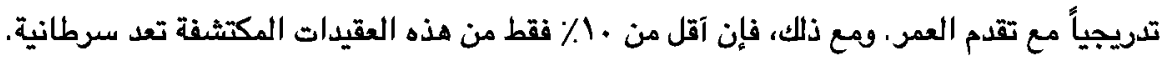

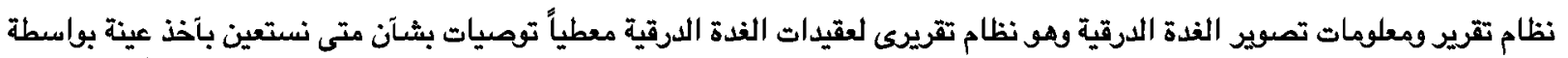

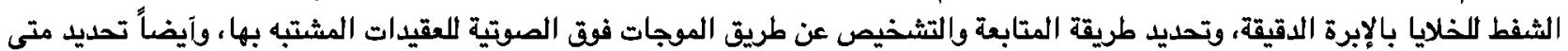

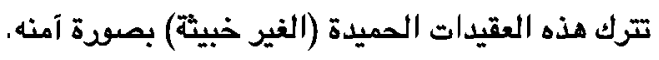

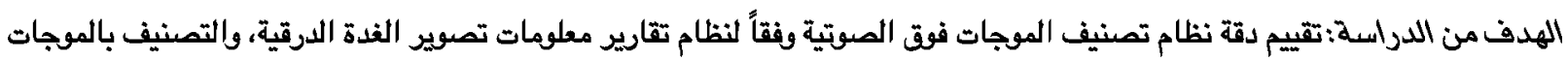

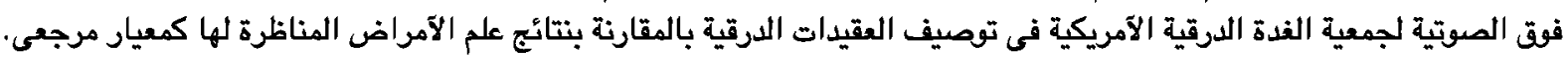

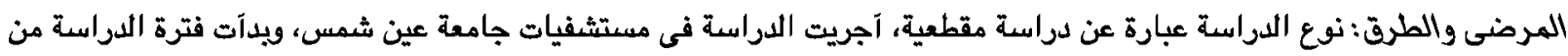

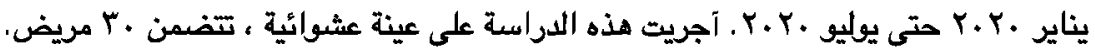

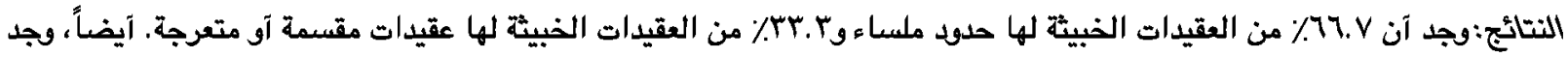

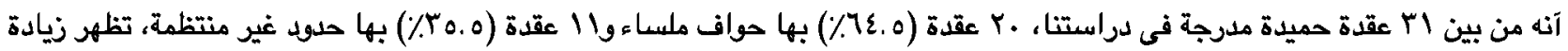
كبيرة فى المجموعة الحميدة من المجموعة الذبيثة. الإستتاجات: يعد تظام تصنيف الموجات فوق الصوتية وفقاً لنظام تقارير معلومات تصوير الفدة الدرقية طريقة بسيطة وعملية لتقييم

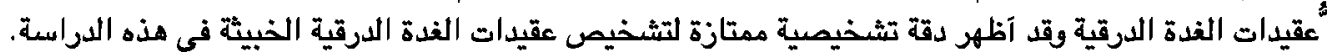

